\title{
Syzygium aromaticum water extract attenuates ethanol-induced gastric injury through antioxidant effects in rats
}

\author{
SEONG EUN JIN ${ }^{1}$, MEE-YOUNG LEE ${ }^{1}$, IN-SIK SHIN ${ }^{2}$, WOO-YOUNG JEON ${ }^{1}$ and HYEKYUNG HA ${ }^{1}$ \\ ${ }^{1}$ K-herb Research Center, Korea Institute of Oriental Medicine, Daejeon 34054; ${ }^{2}$ College of Veterinary Medicine, \\ Chonnam National University, Gwangju 61186, Republic of Korea
}

Received June 2, 2015; Accepted May 3, 2016

DOI: $10.3892 / \mathrm{mmr} .2016 .5269$

\begin{abstract}
The aim of the present study was to investigate whether Syzygium aromaticum water extract (SAWE) has a protective effect against ethanol-induced gastric injury in rats. Acute gastric injury was induced via intragastric administration of absolute ethanol at a dose of $5 \mathrm{ml} / \mathrm{kg}$. SAWE ( 250 or $500 \mathrm{mg} / \mathrm{kg} / \mathrm{day}$ ) or cimetidine $(100 \mathrm{mg} / \mathrm{kg} / \mathrm{day})$, which was used as a positive control, were administered to the rats $2 \mathrm{~h}$ prior to ethanol administration for 3 days. All rats were sacrificed $24 \mathrm{~h}$ following the final ethanol administration. To examine whether SAWE has a gastroprotective effect, assays were performed to assess the contents of malondialdehyde (MDA) and glutathione (GSH), the activities of catalase, glutathione-S-transferase and superoxide dismutase, and an immune-linked immunosorbent assay was performed for prostaglandin $\mathrm{E}_{2}\left(\mathrm{PGE}_{2}\right)$ production in gastric tissues by hematoxylin and eosin and periodic acid-Schiff staining. Histological assessment of the gastric wall was performed. Compared with ethanol treatment alone, treatment with SAWE at a dose of $250 \mathrm{mg} / \mathrm{kg} /$ day significantly decreased the gastric MDA content and increased the GSH content, catalase activity, and production of gastric $\mathrm{PGE}_{2}$. Histological assessment showed that SAWE attenuated inflammatory cell infiltration and the loss of epithelial cells. These findings suggested that SAWE protected against ethanol-induced gastric mucosal injury in the rats. These effects appeared to be associated with antioxidant activity, activation of the production of $\mathrm{PGE}_{2}$, suppression of inflammatory cell infiltration and loss of epithelial cells in the gastric mucosa. Collectively, SAWE may be beneficial in the prevention of gastric disease associated to oxidative stress.
\end{abstract}

\section{Introduction}

Gastritis is a condition involving inflammation, irritation and erosion, which occurs when the endogenous defense mecha-

Correspondence to: Dr Hyekyung Ha, K-herb Research Center, Korea Institute of Oriental Medicine, 1672 Yuseongdae-ro, Yuseong-Gu, Daejeon 34054, Republic of Korea

E-mail: hkha@kiom.re.kr

Key words: Syzygium aromaticum, ethanol, gastric injury, antioxidant nisms of the mucosal barrier cannot protect the organ. Alcohol increases the production of reactive oxygen species (ROS) and oxidative stress, and decreases the levels of antioxidant in a number of cells and tissues, leading to gastric damage (1). ROS provoke severe changes at the cellular level, which can lead to cell death resulting from the marked reactivity. Increased ROS production leads to lipid peroxidation by reacting with the double bonds in unsaturated fatty acids, which causes the formation of multiple electrophilic aldehyde species. These species are capable of forming adducts with proteins, which leads to protein dysfunction (2). Oxidative stress occurs when ROS production exceeds the capacity of the cellular antioxidant system, or when the functioning of the antioxidant defense system is insufficient to neutralize the oxidants (3). Ethanol causes severe oxidative stress in gastric tissue, and a competent antioxidant defense system is important to provide gastric protection (4). Previous studies have reported that antioxidant enzymes protect against ethanol-induced gastric mucosal injury (5-7).

Prostaglandins exert a gastroprotective effect against gastric mucosal injury through the maintenance of gastric mucus synthesis and secretion (8). In particular, prostaglandin $\mathrm{E}_{2}\left(\mathrm{PGE}_{2}\right)$ is important in the regulation of gastric mucus secretion (9). $\mathrm{PGE}_{2}$ has been shown to have protective effects in various gastric injury models (10). However, ethanol reduces mucosal $\mathrm{PGE}_{2}$ content (11).

According to the World Health Organization, $>80 \%$ of the world's population relies on medicinal herbs for their primary healthcare requirements (12). The herbs used for traditional medicine contain a wide range of substances, which are used to prevent or treat various diseases (13). Syzygium aromaticum (SA), one type of medicinal herb, has antioxidant activity (14), antifungal activity (15), a hypoglycemic effect (16), a bone-preserving effect (17), chemopreventive potential in lung cancer (18), effects on the immune response (19) and an antiobesity effect (20). The antioxidant properties of SA suggest that it may be a promising candidate as an antigastritis or antiulcer agent. Therefore, in the present study, whether SA water extract (SAWE) has gastroprotective potential against ethanol-induced gastric mucosal injury in rats was investigated.

\section{Materials and methods}

Preparation of SAWE. SAWE was prepared in K-herb Research Center of Korea Institute of Oriental Medicine (Daejeon, Korea). 
The extraction and high-performance liquid chromatography analysis were performed, as described previously (21).

Ethanol-induced gastritis. Specific-pathogen-free male Sprague-Dawley rats, (200-250 g; 6 weeks old) from Daehan Biolink Co., Ltd. (Chungbuk, Korea) were acclimatized for 1 week prior to the start of the investigation with evaluation of health status. The animals were maintained in environmentally controlled rooms at $23 \pm 3^{\circ} \mathrm{C}$ under a relative humidity of $50 \pm 10 \%$ with a $12 \mathrm{~h}$ light-dark cycle and $12-15$ air changes $/ \mathrm{h}$, as previously described (22).

The present study was performed at the Korea Institute of Oriental Medicine (Daejeon, Republic of Korea), and the protocol was approved by the Institutional Animal Care and Use Committee. All experimental procedures were performed in compliance with the National Institute of Health Guidelines for the Care and Use of Laboratory Animals (23), and the National Animal Welfare Law of Korea (24).

Gastric lesions were induced via intragastric administration of absolute ethanol, according to a previously described method (25-27) with minor modification. A total of 35 rats were divided into five groups ( $\mathrm{n}=7 /$ group) and fasted for $18 \mathrm{~h}$ prior to the experiment. The rats in the control group were orally administered with phosphate-buffered saline (PBS; $5 \mathrm{ml} / \mathrm{kg}$ body weight) as the vehicle, and those in the absolute-ethanol group were administered with absolute ethanol orally ( $5 \mathrm{ml} / \mathrm{kg}$ body weight). The rats in the positive control group were administered with cimetidine (100 $\mathrm{mg} / \mathrm{kg}$ body weight) orally $2 \mathrm{~h}$ prior to the administration of absolute ethanol for 3 days. Cimetidine was used as a positive control drug as it has anti-inflammatory and antioxidative activities, and is used widely in the treatment of gastritis (28). The treatment groups received SAWE (250 or $500 \mathrm{mg} / \mathrm{kg}$ body weight) $2 \mathrm{~h}$ prior to the administration of absolute ethanol for 3 days.

At the end of the 3 days, the rats were sacrificed with an overdose of $100 \mathrm{mg} / \mathrm{kg}$ pentobarbital, performed $24 \mathrm{~h}$ following the final ethanol administration. The stomach was removed, opened along the greater curvature and gently rinsed with PBS. The stomach was stored at $-70^{\circ} \mathrm{C}$ until biochemical analysis.

Biochemical analysis. Biochemical analysis was performed using a previously described method (29). The stomach was cut into small sections and homogenized (1/10 w/v) with tissue lysis/extraction reagent containing protease inhibitors (Sigma-Aldrich, St. Louis, MO, USA). The homogenates were centrifuged at $15,000 \times \mathrm{g}$ for $10 \mathrm{~min}$ at $4^{\circ} \mathrm{C}$ to precipitate the cell debris, the protein concentration of the supernatant was determined using a Protein Assay Dye Reagent Concentrate (Bio-Rad Laboratories, Hercules, CA, USA), according to the manufacturer's protocol. This homogenized sample was used to measure the levels of malondialdehyde (MDA) and glutathione (GSH), and the activities of catalase, glutathione-S-transferase (GST) and superoxide dismutase (SOD). The protein concentrations were measured using Protein Assay Reagent Concentrate (Bio-Rad Laboratories, Inc., Hercules, CA, USA), according to the manufacturer's protocol.

To estimate lipid peroxidation, the content of MDA was measured using a thiobarbituric acid-reactive substances assay kit (BioAssay Systems, Hayward, CA, USA). The GSH content and the activities of antioxidant enzymes, catalase, GST and SOD, were measured using commercial kits (Cayman Chemical Company, Ann Arbor, MI, USA), according to the manufacturer's protocols. The values for the MDA and GSH contents are expressed as $\mathrm{nmol} / \mathrm{mg}$ and $\mu \mathrm{mol} / \mathrm{mg}$ protein, respectively, and the activities of the antioxidant enzymes are expressed as $\mathrm{U} / \mathrm{mg}$ protein.

Measurement of $P G E_{2}$ levels. The concentrations of $\mathrm{PGE}_{2}$ were measured using a previously described method (27). The production of $\mathrm{PGE}_{2}$ was measured in the homogenates of the gastric tissue using an immune-linked immunosorbent assay kit (Cayman Chemical Company), according to the manufacturer's protocol.

Histopathology and periodic acid-Schiff (PAS) histochemistry. The glandular face of the stomach was examined histologically. The stomach tissues were preserved in $10 \%$ buffered-formalin and processed for paraffin block preparation. Sections measuring $\sim 4 \mu \mathrm{m}$ in thickness were stained with hematoxylin (cat. no. MHS-16; Sigma-Aldrich) and eosin (cat. no. HT110-1-32; Sigma-Aldrich) solution, and PAS (IMEB, Inc., San Marcos, CA, USA) to estimate inflammation and mucus production, respectively. The histopathological changes were assessed by microscopy, according to the previously described criteria (29).

Statistical analysis. All data are presented as the mean \pm standard error of the mean. One-way analysis of variance was used to detect significant differences between the control and treatment groups. Dunnett's test was used for multiple comparisons. Statistical analysis was performed using Systat software (version 10; Systat Software Inc., San Jose, CA, USA). P<0.05 was considered to indicate a statistically significant difference.

\section{Results}

Effect of SAWE on lipid peroxidation and GSH content in ethanol-induced gastritis. As shown in Fig. 1A, the concentration of MDA, an end product of lipid peroxidation, was higher in the ethanol group $(130.75 \pm 6.52 \mathrm{nmol} / \mathrm{mg}$ protein; $\mathrm{P}<0.01)$, compared with the control group $(72.05 \pm 3.17 \mathrm{nmol} / \mathrm{mg}$ protein). By contrast, the MDA content was significantly lower, in a dose-dependent manner, in the groups treated with SAWE at $250(64.79 \pm 7.84 \mathrm{nmol} / \mathrm{mg}$ protein; $\mathrm{P}<0.01)$ or $500 \mathrm{mg} / \mathrm{kg}$ $(55.31 \pm 4.23 \mathrm{nmol} / \mathrm{mg}$ protein; $\mathrm{P}<0.01)$, compared with the ethanol group. The positive control cimetidine-treated group also had a lower MDA content $(63.42 \pm 5.33 \mathrm{nmol} / \mathrm{mg}$ protein; $\mathrm{P}<0.01)$, compared with the ethanol group.

GSH content was significantly lower in the ethanol group $(25.49 \pm 3.06 \mu \mathrm{mol} / \mathrm{mg}$ protein; $\mathrm{P}<0.01)$, compared with the control group $(44.32 \pm 1.80 \mu \mathrm{mol} / \mathrm{mg}$ protein; Fig. 1B). By contrast, the GSH contents were higher in the groups treated with SAWE at $250(37.43 \pm 2.93 \mu \mathrm{mol} / \mathrm{mg}$ protein; $\mathrm{P}<0.01)$ or $500 \mathrm{mg} / \mathrm{kg}(33.00 \pm 7.40 \mathrm{nmol} / \mathrm{mg}$ protein), compared with the ethanol group. GSH content was significantly lower in the cimetidine-treated positive control group $(33.80 \pm 1.42 \mu \mathrm{mol} / \mathrm{mg}$ protein; $\mathrm{P}<0.05)$, compared with the ethanol group.

Effect of SAWE on the activities of antioxidant enzymes in ethanol-induced gastritis. As shown in Fig. 2A, cata- 

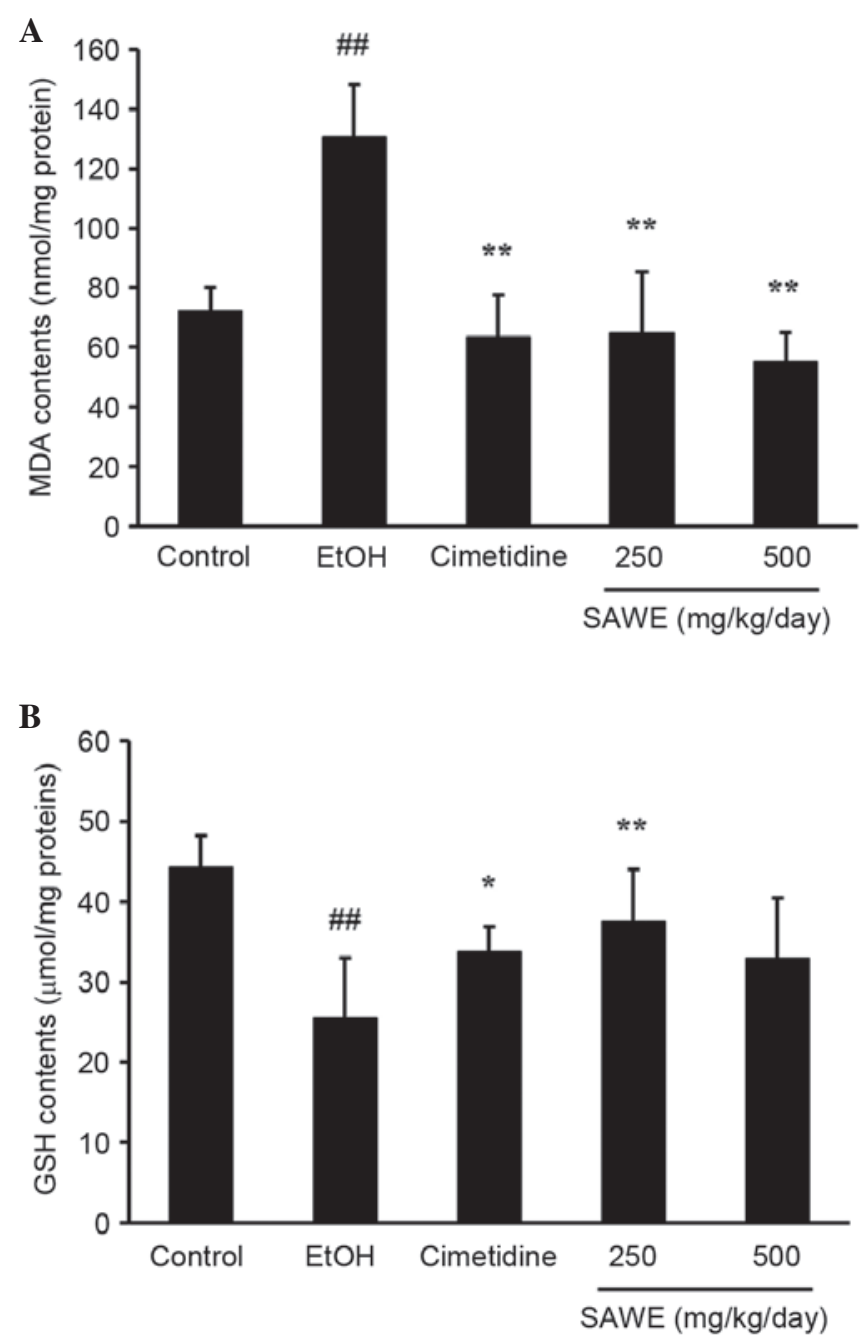

Figure 1. Effects of SAWE treatment on the contents of (A) MDA and (B) GSH in gastric mucosa with EtOH-induced gastric injury. The results are expressed as the mean \pm standard deviation. ${ }^{\# \#} \mathrm{P}<0.01$, compared with the control group; ${ }^{*} \mathrm{P}<0.05$ and ${ }^{* *} \mathrm{P}<0.01$, compared with the EtOH group. SAWE, Syzygium aromaticum water extract; MDA, malondialdehyde; GSH, glutathione.

lase activity was significantly lower in the ethanol group $(26.78 \pm 1.31 \mathrm{U} / \mathrm{mg}$ protein; $\mathrm{P}<0.01)$, compared with the control group $(48.39 \pm 4.26 \mathrm{U} / \mathrm{mg}$ protein; $\mathrm{P}<0.01)$. By contrast, no significant differences in catalase activity were observed in the groups treated with SAWE at 250 $(34.09 \pm 2.77 \mathrm{U} / \mathrm{mg}$ protein) or $500 \mathrm{mg} / \mathrm{kg}(35.04 \pm 4.32 \mathrm{U} / \mathrm{mg}$ protein) or with cimetidine ( $38.39 \pm 1.48 \mathrm{U} / \mathrm{mg}$ protein).However, the GST activity was significantly lower in the ethanol group $(16.03 \pm 1.27 \mathrm{U} / \mathrm{mg}$ protein), compared with that in the control group $(19.53 \pm 0.78 \mathrm{U} / \mathrm{mg}$ protein; $\mathrm{P}<0.01$; Fig. $2 \mathrm{~B})$. The administration of SAWE at 250 or $500 \mathrm{mg} / \mathrm{kg}$ or cimetidine had no significant effect on GST activity, compared with ethanol treatment. SOD activity did not differ significantly between any groups (Fig. 2C).

Effects of SAWE on the production of $P G E_{2}$. The production of $\mathrm{PGE}_{2}$ was lower in the ethanol group $(13.30 \pm 0.88 \mathrm{ng} / \mathrm{mg}$ protein), compared with the control group $(17.81 \pm 1.98 \mathrm{ng} / \mathrm{mg}$ protein; Fig. 3). No significant difference in the production of $\mathrm{PGE}_{2}$ was observed in the cimetidine-treated positive control

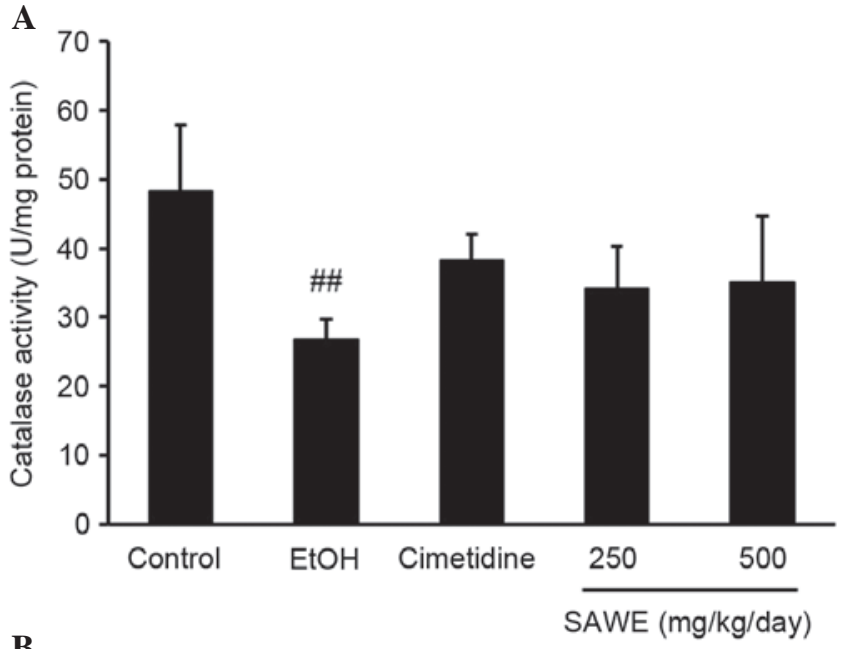

B

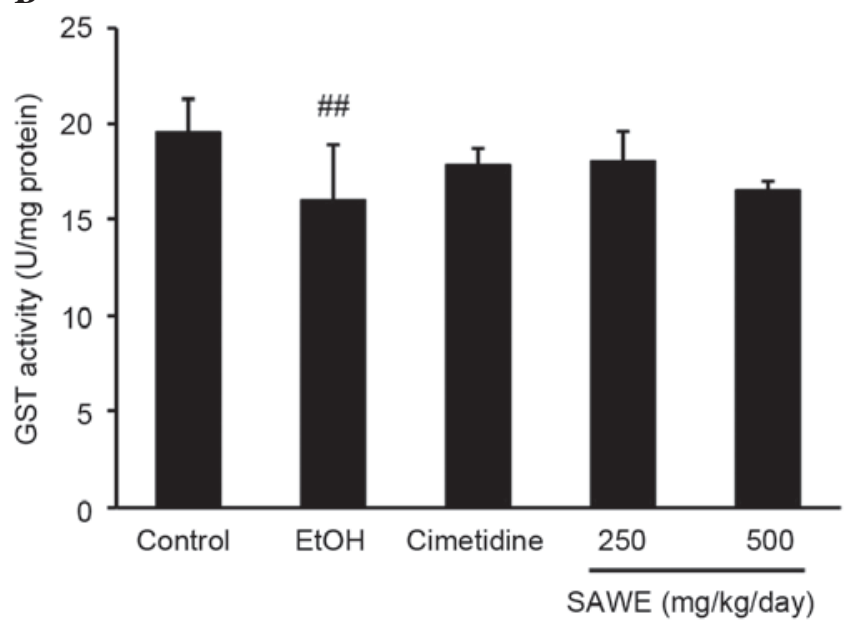

C

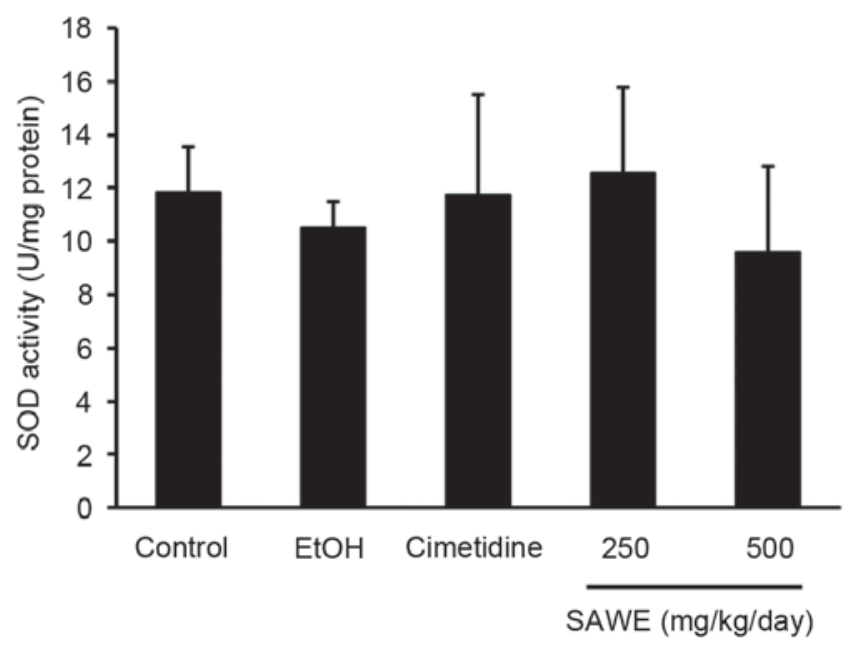

Figure 2. Effects of SAWE on the activity of antioxidant enzymes. The activities of (A) catalase, (B) GST and (C) SOD in gastric mucosa with ethanol-induced gastric injury. The results are expressed as the mean \pm standard deviation. ${ }^{\#} \mathrm{P}<0.01$, compared with the control group. SAWE, Syzygium aromaticum water extract; GST, glutathione-S-transferase; SOD, superoxide dismutase.

group (18.18 $\pm 3.23 \mathrm{ng} / \mathrm{mg}$ protein), compared with the ethanol group. SAWE treatment at a dose of $250(15.98 \pm 2.06 \mathrm{ng} / \mathrm{mg}$ protein) or $500 \mathrm{mg} / \mathrm{kg}(13.88 \pm 1.79 \mathrm{ng} / \mathrm{mg}$ protein) had no significant effects on the production of $\mathrm{PGE}_{2}$, compared with the ethanol treatment group. 


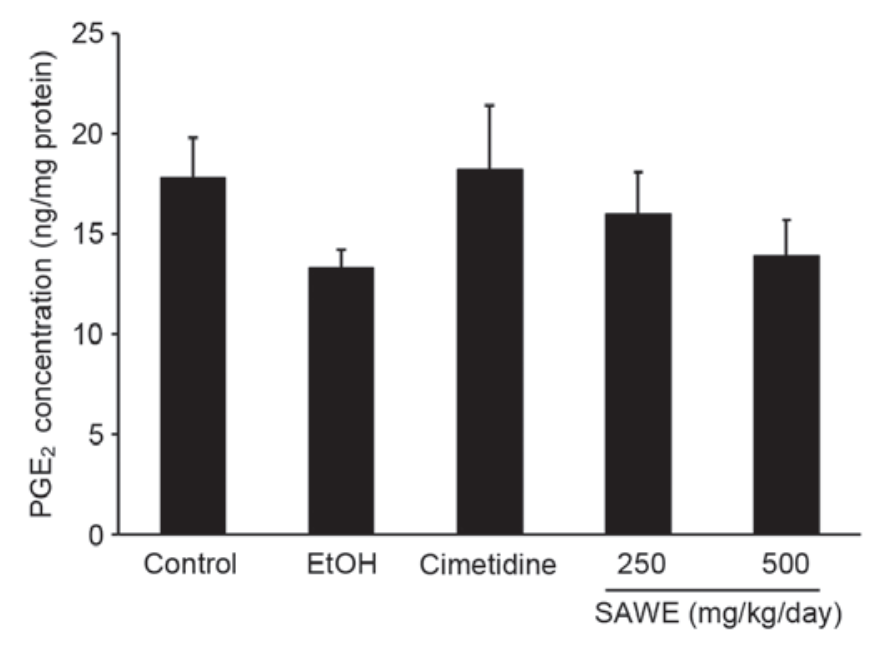

Figure 3. Effects of SAWE on the production of $\mathrm{PGE}_{2}$ in gastric mucosa with ethanol-induced gastric injury. The results are expressed as the mean \pm standard deviation. SAWE, Syzygium aromaticum water extract; $\mathrm{PGE}_{2}$, prostaglandin $\mathrm{E}_{2}$.

PAS staining evaluation of gastric lesions. The PAS staining was higher in the gastric mucosa of the ethanol group, compared with the control group, indicating an increase in glycoprotein content in the gastric mucosa (Fig. 4). By contrast, the SAWE ( 250 or $500 \mathrm{mg} / \mathrm{kg}$ ) and cimetidine-treated groups exhibited normal levels of mucin in the glandular tissue of the stomach, as shown by the increase in magenta staining in the mucosal cell layer, compared with ethanol treatment.

Histological evaluation of gastric lesions. In the control group, normal histological structure of the gastric mucosa was observed (Fig. 5). By contrast, the ethanol group showed inflammatory cell infiltration in the mucosa and submucosa. The administration of SAWE (250 or $500 \mathrm{mg} / \mathrm{kg}$ ) or cimetidine attenuated the loss of epithelial cells and evidence of hemorrhage in the stomach area.

\section{Discussion}

Several medicinal herbs, including Aloe vera, Curcuma longa and Glycyrrhiza glabra, have been reported to possess antiulcer activities (30), and certain phytochemicals in medicinal herbs, including gallic acid, glycyrrhizinic acid, phenolic compounds and flavonoids, have been shown to have gastroprotective effects by regulating gastric mucus secretion or through antioxidant activity (31). Among these, eugenol, gallic acid and ellagic acid, which are abundant constituents of SAWE, have antigastric effects and antioxidant activities (32-34). Based on the previous studies, the present study hypothesized that SAWE, which contains these bioactive components, has a preventive effect against gastric injury.

The administration of ethanol has long been used as a reproducible method to induce gastric injury in experimental animals (35). Ethanol-induced gastric damage is characterized by hemorrhage, mucosal edema, inflammatory cell infiltration and loss of epithelial cells (36). Therefore, the present study, investigated whether SAWE has a protective effect against ethanol-induced gastric injury in rats. The administration of ethanol induced severe gastric lesions, as shown by inflammatory cell infiltration and loss of epithelial cells. By contrast, the administration of SAWE (250 or $500 \mathrm{mg} / \mathrm{kg}$ ) attenuated the gastric injury induced by ethanol.

ROS, including superoxide anions, hydrogen peroxide, hydroxyl radicals, and lipid peroxidation are important in the pathogenesis of gastric mucosal injury $(4,7,37)$. MDA is the final product of lipid peroxidation and is used as an estimate of lipid peroxidation levels (38). Lipid peroxidation is caused by an imbalance between antioxidant defense systems and oxidative damage, which affects cell membranes. MDA content was higher in the ethanol group, compared with the SAWE-treated groups $(250$ or $500 \mathrm{mg} / \mathrm{kg}$ ) and cimetidine-treated group. These results suggested that SAWE had protective effects against ethanol-induced gastric injury by inhibiting lipid peroxidation.

GSH, an endogenous antioxidant, reacts with peroxides and toxic oxygen radicals, including hydroxyl ions and singlet oxygen, to protect cells from damage (39). The present study found that the GSH content was significantly lower in the ethanol group, compared with the control group. By contrast, GSH contents were higher in the SAWE-treated groups (250 or $500 \mathrm{mg} / \mathrm{kg}$ ) and cimetidine-treated group, compared with the ethanol group. These findings indicated that pretreatment with SAWE protected the gastric mucosa from ethanol-induced gastric injury by increasing the GSH content.

The important cellular antioxidant enzymes, including catalase, GST, and SOD, contribute to the gastric oxidative-antioxidative balance. Decreases in the activities of these enzymes in the gastric mucosa of rats exposed to ethanol leads to the accumulation of ROS and, consequently, to an increase in MDA levels (40). In the present study, ethanol decreased the activities of catalase and GST, suggesting the importance of these enzymes in the pathogenesis of gastric injury. There were no significant changes in the activities of catalase or GST in the low-dose SAWE-treated group $(250 \mathrm{mg} / \mathrm{kg}$ ) or the cimetidine-treated group, compared with the ethanol group. No alterations in SOD activity were observed in any groups. These results suggested that SAWE enhanced the cellular antioxidant system, which may provide protection against ethanol-induced gastric injury.

PGs are key molecules, which activate ulcer-healing mechanisms and are synthesized in the gastric mucosal cells by cyclooxygenases. PGs stimulate the secretion of bicarbonates and mucus, promote ulcer healing and inhibit the secretion of gastric acid. $\mathrm{PGE}_{2}$, one of the major PGs of the gastric mucosa, can inhibit the secretion of gastric acid (41). The ethanol-induced depletion of gastric mucus has been described previously (42), and this may be caused by an inhibitory effect on the gastric production of $\mathrm{PGE}_{2}$ (43). In the present study, the production of $\mathrm{PGE}_{2}$ was reduced in the ethanol group, whereas the concentration of $\mathrm{PGE}_{2}$ was higher in the rats treated with SAWE at $250 \mathrm{mg} / \mathrm{kg} / \mathrm{day}$, compared with the concentration in the ethanol group. The secretion of mucus observed in the SAWE-treated group may have been attributed to the increased $\mathrm{PGE}_{2}$ production observed in the gastric mucosa.

In conclusion, SAWE had a protective effect against ethanol-induced gastric injury by improving antioxidative status and increasing $\mathrm{PGE}_{2}$ production, and by suppressing inflammatory cell infiltration and loss of epithelial cells in 
A

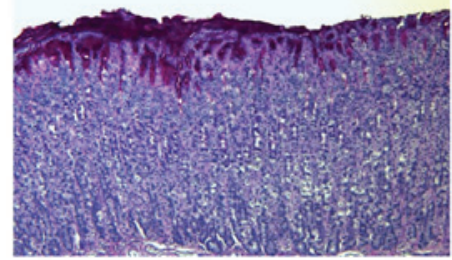

D
B

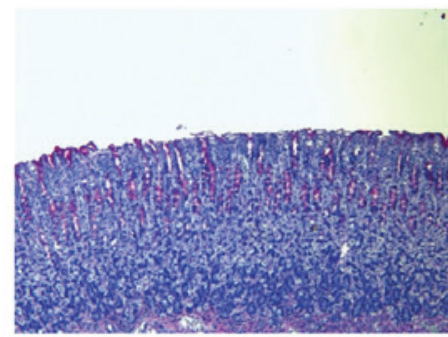

C

$\mathbf{E}$
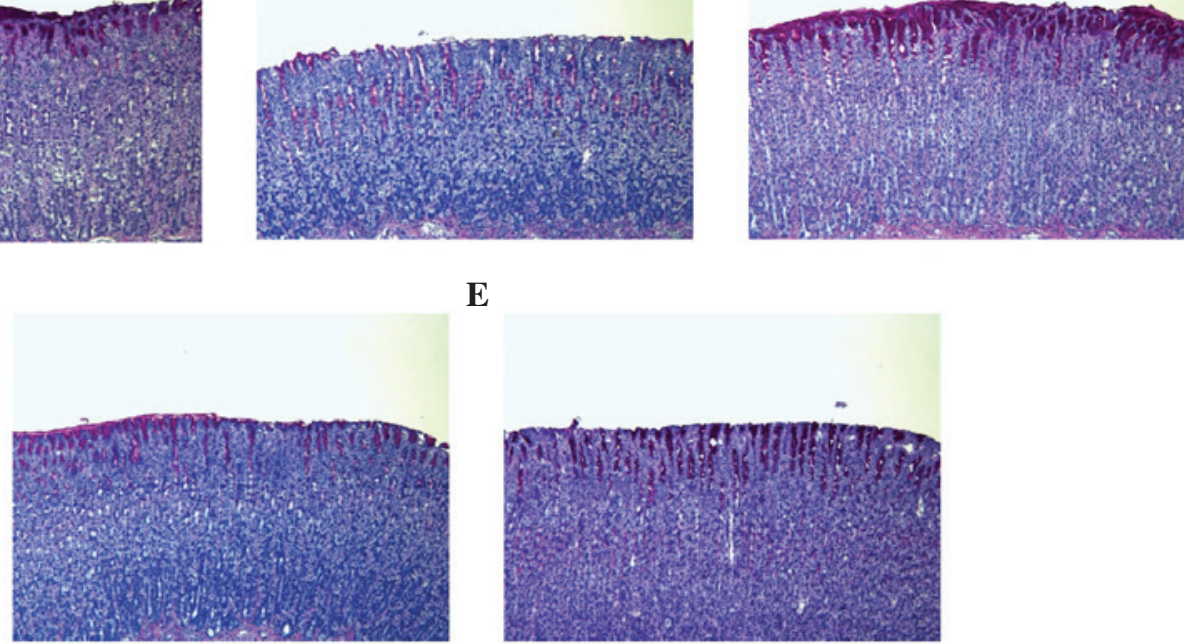

Figure 4. Effects of SAWE on PAS staining in gastric mucosa with ethanol-induced gastric injury. Histological sections were stained with PAS, and images were captured (magnification, x50). (A) Control group; (B) EtOH group; (C) ethanol+cimetidine (100 mg/kg/day); (D) EtOH+SAWE (250 mg/kg/day) group; (E) EtOH+SAWE $(500 \mathrm{mg} / \mathrm{kg} / \mathrm{day})$ group. SAWE, Syzygium aromaticum water extract; PAS, periodic acid-Schiff.

A

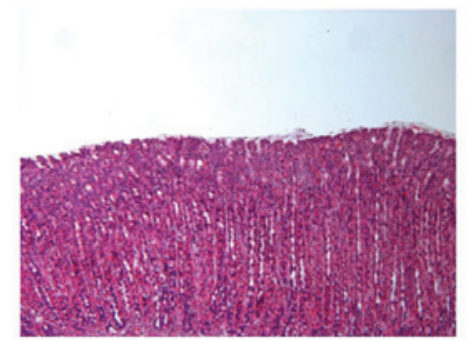

D
B

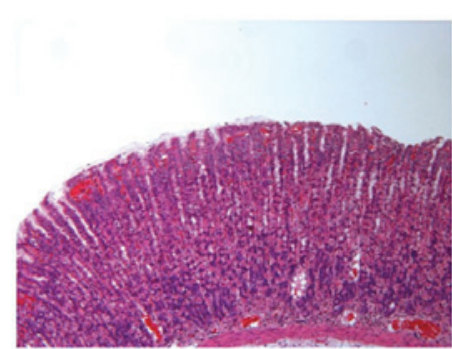

C

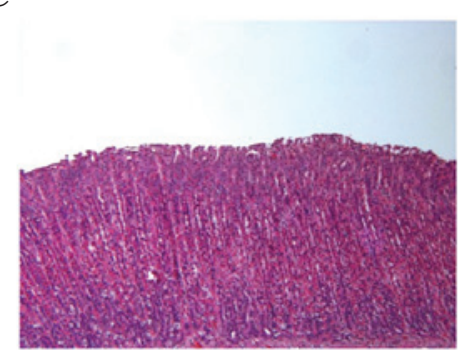

$\mathbf{E}$

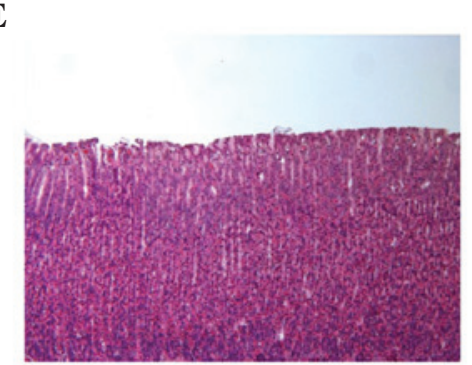

Figure 5. Histopathological examination of gastric mucosa with ethanol-induced gastric injury. Histological sections were stained using hematoxylin and eosin, and images were captured (magnification, x50). (A) Control group; (B) EtOH group; (C) EtOH+cimetidine (100 mg/kg/day) group; (D) EtOH+SAWE (250 mg/kg/day) group; (E) EtOH+SAWE (500 mg/kg/day) group. SAWE, Syzygium aromaticum water extract.

the gastric mucosa. These findings suggested that SAWE has potential for further development as a treatment against alcohol-induced gastric injury.

\section{Acknowledgements}

This study was supported by a grant 'Evaluation of Herb-Herb Interaction by Array Methods funded by the Korea Institute of Oriental Medicine' from the Korea Institute of Oriental Medicine (grant no. K12271).

\section{References}

1. Oliveira CP, Kassab P, Lopasso FP, Souza HP, Janiszewski M, Laurindo FR, Iriya K and Laudanna AA: Protective effect of ascorbic acid in experimental gastric cancer: Reduction of oxidative stress. World J Gastroenterol 9: 446-448, 2003.

2. Cederbaum AI: Introduction-serial review: Alcohol, oxidative stress and cell injury. Free Radic Biol Med 31: 1524-1526, 2001.

3. Sasaki M and Joh T: Oxidative stress and ischemia-reperfusion injury in gastrointestinal tract and antioxidant, protective agents. J Clin Biochem Nutr 40: 1-12, 2007. 
4. La Casa C, Villegas I, Alarcón de la Lastra C, Motilva V and Martín Calero MJ: Evidence for protective and antioxidant properties of rutin, a natural flavone, against ethanol induced gastric lesions. J Ethnopharmacol 71: 45-53, 2000.

5. Moghadamtousi SZ, Rouhollahi E, Karimian H, Fadaeinasab M, Abdulla MA and Kadir HA: Gastroprotective activity of Annona muricata leaves against ethanol-induced gastric injury in rats via Hsp70/Bax involvement. Drug Des Devel Ther 8: 2099-2110, 2014.

6. Alvarez-Suarez JM, Dekanski D, Ristić S, Radonjić NV, Petronijević ND, Giampieri F, Astolfi P, González-Paramás AM, Santos-Buelga C, Tulipani S, et al: Strawberry polyphenols attenuate ethanol-induced gastric lesions in rats by activation of antioxidant enzymes and attenuation of MDA increase. PLoS One 6: e25878, 2011.

7. Kahraman A, Erkasap N, Köken T, Serteser M, Aktepe F and Erkasap S: The antioxidative and antihistaminic properties of quercetin in ethanol-induced gastric lesions. Toxicology 183 133-142, 2003.

8. Ishihara K, Kuwata H, Ohara S, Okabe H and Hotta K: Changes of rat gastric mucus glycoproteins in cytoprotection: Influences of prostaglandin derivatives. Digestion 39: 162-171, 1988.

9. Hawkey CJ and Rampton DS: Prostaglandins and the gastrointestinal mucosa: Are they important in its function, disease, or treatment? Gastroenterology 89: 1162-1188, 1985.

10. Takeuchi K, Kato S and Tanaka A: Gastrointestinal cytoprotection by prostaglandin E and EP receptor subtypes. Nihon Yakurigaku Zasshi 117: 274-282, 2001 (In Japanese).

11. Zhao W, Zhu F, Shen W, Fu A, Zheng L, Yan Z, Zhao L and Fu G: Protective effects of DIDS against ethanol-induced gastric mucosal injury in rats. Acta Biochim Biophys Sin (Shanghai) 41: 301-308, 2009

12. World Health Organization: General guidelines for methodologies on research and evaluation of traditional medicine. World Health Organization, Geneva, 2000.

13. Duraipandiyan V, Ayyanar M and Ignacimuthu S: Antimicrobial activity of some ethnomedicinal plants used by Paliyar tribe from Tamil Nadu, India. BMC Complement Altern Med 6: 35, 2006.

14. Chaieb K, Zmantar T, Ksouri R, Hajlaoui H, Mahdouani K, Abdelly $\mathrm{C}$ and Bakhrouf A: Antioxidant properties of the essential oil of Eugenia caryophyllata and its antifungal activity against a large number of clinical Candida species. Mycoses 50 403-406, 2007.

15. Pinto E, Vale-Silva L, Cavaleiro C and Salgueiro L: Antifungal activity of the clove essential oil from Syzygium aromaticum on Candida, aspergillus and dermatophyte species. J Med Microbiol 58: 1454-1462, 2009.

16. Kuroda M, Mimaki Y, Ohtomo T, Yamada J, Nishiyama T, Mae T, Kishida H and Kawada T: Hypoglycemic effects of clove (Syzygium aromaticum flower buds) on genetically diabetic KK-Ay mice and identification of the active ingredients. J Nat Med 66: 394-399, 2012.

17. Karmakar S, Choudhury M, Das AS, Maiti A, Majumdar S and Mitra C: Clove (Syzygium aromaticum Linn) extract rich in eugenol and eugenol derivatives shows bone-preserving efficacy. Nat Prod Res 26: 500-509, 2012.

18. Banerjee S, Panda CK and Das S: Clove (Syzygium aromaticum L.), a potential chemopreventive agent for lung cancer. Carcinogenesis 27: 1645-1654, 2006.

19. Halder S, Mehta AK, Mediratta PK and Sharma KK: Essential oi of clove (Eugenia caryophyllata) augments the humoral immune response but decreases cell mediated immunity. Phytother Res 25: 1254-1256, 2011

20. Jung CH,Ahn J,JeonTI,Kim TW and Ha TY: Syzygium aromaticum ethanol extract reduces high-fat diet-induced obesity in mice through downregulation of adipogenic and lipogenic gene expression. Exp Ther Med 4: 409-414, 2012.

21. Kim JH, Seo CS, Kim SS and Ha H: Simultaneous determination of gallic acid, ellagic acid, and eugenol in Syzygium aromaticum and verification of chemical antagonistic effect by the combination with Curcuma aromatica using regression analysis. J Anal Methods Chem 2013: 375294, 2013.

22. Jeon WY, Shin IS, Shin HK and Lee MY: Gastroprotective effect of the traditional herbal medicine, Sipjeondaebo-tang water extract, against ethanol-induced gastric mucosal injury. BMC Complement Altern Med 14: 373, 2014
23. National Research Council (US) Committee for the Update of the Guide for the Care and Use of Laboratory Animals: Guide for the care and use of laboratory animals. 8th edition. National Academies Press (US), Washington (DC), 2011.

24. Ministry of Food and Drug Safety. Laboratory Animal Act, Act No. 11987, 2013

25. Robert A, Nezamis JE, Lancaster C and Hanchar AJ Cytoprotection by prostaglandins in rats. Prevention of gastric necrosis produced by alcohol, $\mathrm{HCl}, \mathrm{NaOH}$, hypertonic $\mathrm{NaCl}$, and thermal injury. Gastroenterology 77: 433-443, 1979.

26. Ishida K, Kojima R, Tsuboi M, Tsuda Y and Ito M: Effects of artichoke leaf extract on acute gastric mucosal injury in rats. Biol Pharm Bull 33: 223-229, 2010.

27. Lee MY, Shin IS, Jeon WY, Seo CS, Ha H, Huh JI and Shin HK: Protective effect of Bojungikki-tang, a traditional herbal formula, against alcohol-induced gastric injury in rats. J Ethnopharmacol 142: 346-353, 2012.

28. Hernández-Muñoz R and Montiel-Ruíz F: Reversion by histamine H2-receptor antagonists of plasma membrane alterations in ethanol-induced gastritis. Dig Dis Sci 41: 2156-2165, 1996.

29. Shin IS, Jeon WY, Shin HK, Cha SW and Lee MY: Banhabaekchulchunma-tang, a traditional herbal formula attenuates absolute ethanol-induced gastric injury by enhancing the antioxidant status. BMC Complement Altern Med 13: 170 2013.

30. Rai N, Kumar N, Gautam P and Rawat P: Herbal plants as potent candidate for anti-ulcer drug development. Environ Conserv J 13: 187-189, 2012.

31. Sen S, Chakraborty R, De B and Mazumder J: Plants and phytochemicals for peptic ulcer: An overview. Pharmacogn Rev 3: 270, 2009.

32. Jung J, Lee JH, Bae KH and Jeong CS: Anti-gastric actions of eugenol and cinnamic acid isolated from Cinnamomi Ramulus. Yakugaku Zasshi 131: 1103-1110, 2011.

33. Abdelwahab SI: Protective mechanism of gallic acid and its novel derivative against ethanol-induced gastric ulcerogenesis: Involvement of immunomodulation markers, Hsp70 and Bcl-2-associated X protein. Int Immunopharmacol 16: 296-305, 2013.

34. Iino T, Tashima K, Umeda M, Ogawa Y, Takeeda M, Takata K and Takeuchi K: Effect of ellagic acid on gastric damage induced in ischemic rat stomachs following ammonia or reperfusion. Life Sci 70: 1139-1150, 2002

35. Qodriyah HM and Asmadi AY: Eurycoma longifolia in Radix for the treatment of ethanol-induced gastric lesion in rats. Pak J Biol Sci 16: 1815-1818, 2013

36. Guslandi M: Effect of ethanol on the gastric mucosa. Dig Dis 5: 21-32, 1987

37. Mizui T, Sato H, Hirose F and Doteuchi M: Effect of antiperoxidative drugs on damage induced by ethanol in rats. Life Sci 41: 755-763, 1987.

38. Dursun H, Bilici M, Albayrak F, Ozturk C, Saglam MB, Alp HH and Suleyman $\mathrm{H}$ : Antiulcer activity of fluvoxamine in rats and its effect on oxidant and antioxidant parameters in stomach tissue. BMC Gastroenterol 9: 36, 2009.

39. Cadirci E, Suleyman H, Aksoy H, Halici Z, Ozgen U, Koc A and Ozturk N: Effects of Onosma armeniacum root extract on ethanol-induced oxidative stress in stomach tissue of rats. Chem Biol Interact 170: 40-48, 2007.

40. Olaleye SB and Farombi EO: Attenuation of indomethacin- and $\mathrm{HCl} /$ ethanol-induced oxidative gastric mucosa damage in rats by kolaviron, a natural biflavonoid of Garcinia kola seed. Phytother Res 20: 14-20, 2006.

41. Adhikary B, Yadav SK, Roy K, Bandyopadhyay SK and Chattopadhyay S: Black tea and theaflavins assist healing of indomethacin-induced gastric ulceration in mice by antioxidative action. Evid Based Complement Alternat Med 2011: 546560, 2011.

42. Slomiany A, Morita M, Sano S, Piotrowski J, Skrodzka D and Slomiany BL: Effect of ethanol on gastric mucus glycoprotein synthesis, translocation, transport, glycosylation, and secretion. Alcohol Clin Exp Res 21: 417-423, 1997.

43. Tsukada H,Zielenski J, Mizuta K, Slomiany BL and Slomiany A: Prostaglandin protection against ethanol-induced gastric injury: Regulatory effect on the mucus glycoprotein metabolism. Digestion 36: 201-212, 1987. 